\title{
MicroRNAs as the promising markers of comorbidities in childhood obesity - a systematic review
}

\author{
Michał Hutny ${ }^{1}$, Jagoda Hofman ${ }^{1}$ Agnieszka Zachurzok ${ }^{2}$ and Paweł Matusik 2,* \\ 1 Scientific Society of Medical Students, Faculty of Medical Sciences in Katowice, Medical University of \\ Silesia, Katowice, Poland; dziekanat-katlek@sum.edu.pl \\ 2 Department of Pediatrics and Pediatric Endocrinology, Faculty of Medical Sciences in Katowice, Medical \\ University of Silesia, Katowice, Poland; endo_sk6@sum.edu.pl \\ * Correspondence: endocrin@wp.pl
}

\begin{abstract}
Rising child obesity rate creates a need for tools quantifying metabolic changes in obese children and adolescents for purposes of comorbidities early detection or prevention. A candidate for such role seem to be miRNAs - in vivo serving as the suppressing factors of the gene expression. The aim of this study was to review the recent discoveries in this field and to conclude directions of research or application of studied molecules. Repeated browsing of databases, followed by screening for eligibility of results, led to final approval of 9 articles. Filtered studies examined the differences in miRNA (miR) expression levels of obese subjects and children suffering from obesity comorbidities. Studies concerning the endothelial dysfunction (ED) identified miR-630 as a possible treatment option. Search for the alternative markers in diagnosis of non-alcoholic fatty liver disease (NAFLD) suggested value of miR-199a-5p and miR-122. MiR-486, miR-146b and miR-15b may serve as a panel of markers grading the development of type 2 diabetes mellitus (T2DM) in children, although further research raised doubts in that matter. Another panel of miRNA molecules was indicated as useful in early detection of alterations leading to metabolic syndrome (MetS). No valid link between studied miRNAs and atherosclerosis (AS) was found. MiRNAs seem to be promising prognostic markers for the diagnosis of NAFLD, T2DM and MetS in children. Further studies are required to support these findings.
\end{abstract}

Keywords: miRNAs, Obesity, Children, Non-alcoholic fatty liver disease; Type 2 diabetes mellitus; Endothelial dysfunction

\section{Introduction}

Obesity in children is one of the most demanding challenges emerging in the modern world of pediatric medicine. Despite various prevention programs, analyses and researches, its occurrence is still high [1], creating more and more danger to the youth. Complications of pediatric obesity revolve mostly around endothelial dysfunction (ED) [2], non-alcoholic fatty liver disease (NAFLD) [3], diabetes mellitus (DM) [4] and atherosclerosis (AS) [5].

The possibility to quantify the progress of aforementioned diseases is necessary in order to overcome the risk of developing those comorbidities in obese children population. The range of available markers and tests still leaves a field for expansion. A field which in many cases might be taken by microRNAs (miRNAs). MiRNAs are small, non-coding molecules that play suppressive role in expression of genes by binding to 3'UTR end of their target messenger RNA (mRNA). They can be found in body tissues or fluids, like saliva, plasma, serum or whole blood, being encapsulated into extracellular vesicles (EV) or as circulating miRNA [6,7]. Changes in profile of the circulating and tissue miRNAs have direct impact on functionality of biomolecular processes in tissues and organs, leading to the development of permanent changes in body and various diseases, even neoplasms $[7,8]$. Considering the easy accessibility of materials rich in miRNAs, further examinations of 
correlation between the miRNA levels and diseases might lead to creation of diagnostic and prognostic markers of high sensitivity and specificity.

Research concerning miRNAs are nowadays one of the more popular scopes of interest in numerous branches of medicine. Lately the differences in miRNA profiles between obese and nonobese children have been investigated $[9,10]$. Up to date no systematic reviews concentrating solely on the dysregulation of miRNA expression in comorbidities of pediatric obesity have been published. Aim of this study was to gather the newest research results in this matter., answering the question: "What are the possible applications of miRNA molecules in diagnosis, prediction and treatment of obesity comorbidities in pediatric population?", in accordance to "participants, interventions, comparisons, outcomes, and study design (PICOS)" scheme.

\section{Materials and Methods}

During the research the entry terms were formulated based on the following scheme (in the presented order):

- • - Subject group: "child obesity" OR "childhood obesity" OR "obese children" OR "pediatric obesity" OR "overweight children" OR "adolescent obesity"

AND

• • Comorbidity: "complications" OR "comorbidities" OR "NAFLD" OR "non-alcoholic fatty liver disease" OR "liver" OR "fatty liver" OR "CVD" OR "cardiovascular diseases" OR "hypertension" OR "metabolic syndrome" OR "puberty" OR "asthma" OR "obstructive sleep apnea" OR "-"

AND

• • Marker: "miRNA" OR "miR"

Adequate filters regarding publication dates (up to 5 years) and text availability were applied. The repeated results of search were ruled out.

Retrieved data underwent further screening on basis of titles, abstracts and keywords, according to Inclusion and Exclusion criteria, leading to exclusion of reviews, systematic reviews, author manuscripts, personal communication, letters to editor, conference material, case reports. Articles concerning the miRNA markers of obesity in children itself, as well as the studies of miRNA not obtained from blood or plasma were ruled out, due to relevance and accessibility criteria of future markers. Inadequate matching of experimental and control groups in the matter of age or exceeding upper age threshold were also the discriminating factor.

The quality of retrieved studies was assessed at the level of data synthesis, concerning the quality of methodology, as well as relevance of the results. The principal measures of differentiating potential were AUC score, fold change and $p$-values.

\section{Results}

Multiple browsing of databases: PubMed, askMEDLINE, Wiley Online Library and Elsevier, conducted in span of January 2020 - November 2020 using search strategy presented in Materials and Methods section, have returned a total of 1729 results. That number has been reduced to 220 individual articles by excluding 1509 repetitions. The remaining have been found eligible for further title and abstract valuation, which in return accepted 24 studies as fitting for whole text reading according to the Inclusion and Exclusion Criteria [see Table 1]. In total 9 studies fully met the Inclusion and Exclusion Criteria. 
Table 1. Criteria used in article selection process.

\begin{tabular}{|c|c|}
\hline INCLUSION CRITERIA & EXCLUSION CRITERIA \\
\hline $\begin{array}{l}\text { English literature published in last } 5 \text { years } \\
\text { Studies in human subjects } \\
\text { Pediatric population }(<19 \text { yo }) \\
\text { Studies examining miRNA profiles of obese } \\
\text { patients }\end{array}$ & $\begin{array}{l}\text { Publication type: reviews, systematic reviews, } \\
\text { author manuscripts, personal communication, } \\
\text { letters to editor, conference material, case report } \\
\text { Studies based on miRNA from body fluids other } \\
\text { than blood } \\
\text { Studies not linking miRNA of obese patients to } \\
\text { any comorbidity } \\
\text { Subjects exceeding at the study time the age } \\
\text { criterium of pediatric group ( } \geq 19 \text { yo) } \\
\text { Control group inadequate in terms of age to Study } \\
\text { group } \\
\text { Subjects diagnosed with comorbidity other than } \\
\text { the examined one }\end{array}$ \\
\hline
\end{tabular}

The process of data collection for this review is presented in Figure 1 below. 
Figure 1. Flow diagram of research process

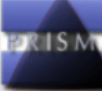

\section{PRISMA 2009 Flow Diagram}
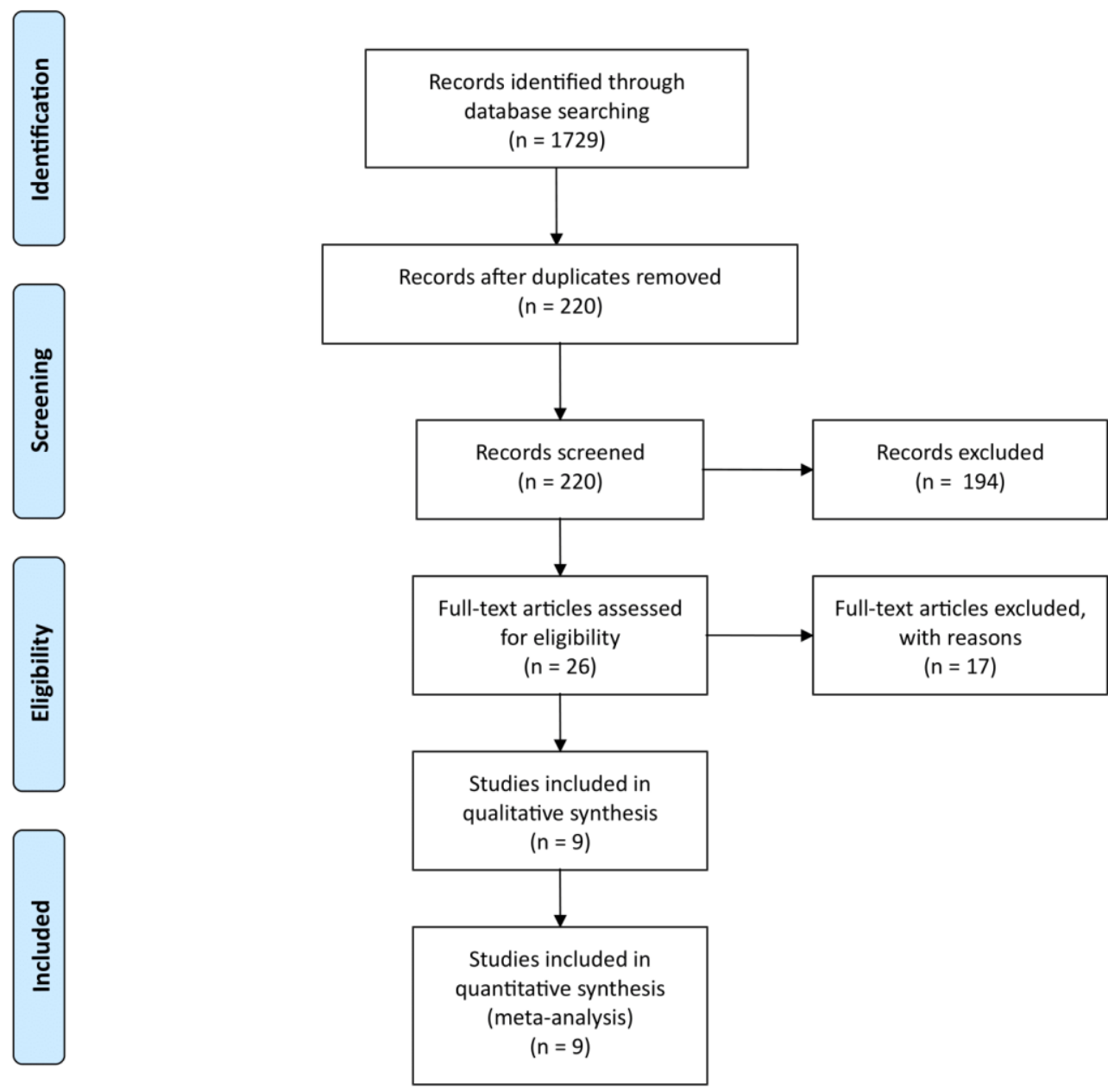

From: Moher D, Liberati A, Tetzlaff J, Altman DG, The PRISMA Group (2009). Preferred Reporting Items for Systematic Reviews and MetaAnalyses: The PRISMA Statement. PLoS Med 6(7): e1000097. doi:10.1371/journal.pmed1000097

For more information, visit www.prisma-statement.org.

Main characteristics of selected articles can be found in Table 2. 
Table 2. Summary of article characteristics

\begin{tabular}{|c|c|c|c|c|c|c|}
\hline Number & Title of article & Authors & Year & $\begin{array}{c}\text { Complication } \\
\text { of obesity }\end{array}$ & $\begin{array}{c}\text { Number of } \\
\text { subjects }\end{array}$ & $\begin{array}{c}\text { Markers } \\
\text { investigated }\end{array}$ \\
\hline 1. & $\begin{array}{l}\text { Improvement of } \\
\text { microvascular } \\
\text { endothelial } \\
\text { dysfunction } \\
\text { induced by } \\
\text { exercise and diet is } \\
\text { associated with } \\
\text { microRNA-126 in } \\
\text { obese adolescents } \\
\text { [11] }\end{array}$ & Donghui et al. & 2019 & ED & 67 & miR-126 \\
\hline 2. & $\begin{array}{c}\text { Circulating } \\
\text { microRNAs as } \\
\text { Potential } \\
\text { Biomarkers of } \\
\text { Endothelial } \\
\text { Dysfunction in } \\
\text { Obese Children } \\
\text { [12] }\end{array}$ & Khalyfa et al. & 2016 & ED & 70 & $\begin{array}{l}\operatorname{miR}-125 a-5 p \\
\operatorname{miR}-342-3 p \\
\operatorname{miR}-365 b-3 p\end{array}$ \\
\hline 3. & $\begin{array}{l}\text { Circulating Plasma } \\
\text { Extracellular } \\
\text { Microvesicle } \\
\text { MicroRNA Cargo } \\
\text { and Endothelial } \\
\text { Dysfunction in } \\
\text { Children with } \\
\text { Obstructive Sleep } \\
\text { Apnea [13] }\end{array}$ & Khalyfa et al. & 2016 & ED & 69 & $\begin{array}{c}\text { miR-16-5p } \\
\text { miR-451a } \\
\text { miR-5100 } \\
\text { miR-630 } \\
\text { miR-4665-3p }\end{array}$ \\
\hline 4. & $\begin{array}{c}\text { Elevation of } \\
\text { circulating } \\
\text { microRNA levels } \\
\text { in obese children } \\
\text { compared to } \\
\text { healthy controls } \\
{[14]}\end{array}$ & $\begin{array}{c}\text { Thompson et } \\
\text { al. }\end{array}$ & 2017 & NAFLD & 30 & $\begin{array}{c}\text { miR-15b-5p } \\
\text { miR-199a-5p } \\
\text { miR-222-3p } \\
\text { miR-223-5p } \\
\text { miR-34a-5p } \\
\text { miR-122-5p } \\
\text { miR-23a-5p } \\
\text { miR-27b-3p } \\
\text { miR-21-5p } \\
\text { miR-34a-5p } \\
\text { miR-451-5p } \\
\text { miR-192-5p } \\
\text { miR-16-5p } \\
\text { miR-29a-3p } \\
\text { miR-150-5p } \\
\text { miR-214-3p } \\
\text { miR-375 } \\
\text { miR-155-5p } \\
\text { miR-191-5p } \\
\text { miR-103a-5p }\end{array}$ \\
\hline
\end{tabular}




\begin{tabular}{|c|c|c|c|c|c|c|}
\hline 5. & $\begin{array}{l}\text { Circulating levels } \\
\text { of miR-122 and } \\
\text { nonalcoholic fatty } \\
\text { liver disease in pre- } \\
\text { pubertal obese } \\
\text { children [15] }\end{array}$ & Brandt et al. & 2017 & NAFLD & 147 & miR-122 \\
\hline 6. & $\begin{array}{c}\text { Change in } \\
\text { circulating } \\
\text { microRNA profile } \\
\text { of obese children } \\
\text { indicates future } \\
\text { risk of adult } \\
\text { diabetes [16] }\end{array}$ & Cui et al. & 2018 & $\mathrm{~T} 2 \mathrm{DM}$ & 718 & $\begin{array}{c}\mathrm{miR}-486 \\
\mathrm{miR}-146 \mathrm{~b} \\
\mathrm{miR}-15 \mathrm{~b}\end{array}$ \\
\hline 7. & $\begin{array}{c}\text { Association } \\
\text { between } \\
\text { circulating } \\
\text { microRNAs } 486, \\
\text { 146b and } 15 \mathrm{~b} \text { and } \\
\text { serum betatrophin } \\
\text { levels in obese; } \\
\text { type } 2 \text { diabetic and } \\
\text { non-diabetic } \\
\text { children [17] }\end{array}$ & Mohany et al. & 2020 & T2DM & 120 & $\begin{array}{c}\mathrm{miR}-486 \\
\mathrm{miR}-146 \mathrm{~b} \\
\mathrm{miR}-15 \mathrm{~b}\end{array}$ \\
\hline 8. & $\begin{array}{l}\text { Circulating } \\
\text { microRNAs and } \\
\text { adipokines as } \\
\text { markers of } \\
\text { metabolic } \\
\text { syndrome in } \\
\text { adolescents with } \\
\text { obesity [18] }\end{array}$ & Al-Rawaf & 2020 & MetS & 250 & $\begin{array}{c}\text { miR-142-3p } \\
\text { miR-140-5p } \\
\text { miR-222 } \\
\text { miR-143 } \\
\text { miR-130 } \\
\text { miR-532-5p } \\
\text { miR-423-5p } \\
\text { miR-520c-3p } \\
\text { miR-146a } \\
\text { miR-15a }\end{array}$ \\
\hline 9. & $\begin{array}{l}\text { Cholesterol efflux } \\
\text { alterations in } \\
\text { adolescent obesity: } \\
\text { role of adipose- } \\
\text { derived } \\
\text { extracellular } \\
\text { vesical microRNAs } \\
{[19]}\end{array}$ & Barberio et al. & 2019 & AS & 93 & $\begin{array}{l}\text { miR-3129-5p } \\
\text { miR-20b } \\
\text { miR9-5p } \\
\text { miR-320d } \\
\text { miR301a-5p } \\
\text { miR-155-5p }\end{array}$ \\
\hline
\end{tabular}

Abbreviations: AS, atherosclerosis; ED, endothelial dysfunction; MetS, metabolic syndrome; miR, miRNA; NAFLD, non-alcoholic fatty liver disease; T2DM, type 2 diabetes mellitus

Enrolled studies concentrated on relation between obesity and its 5 comorbidities. Their methodology is discussed below in subsections separate for each complication. 


\subsection{Endothelial dysfunction}

The highest number of articles was linked to ED - a total of 3 papers (articles 1.; 2.; 3.). In order to qualify the subjects to two groups: normal endothelial function (NEF) and endothelial dysfunction (ED), all patients have undergone the Reactive Hyperemic Index (RHI) measurement, which is partly dependent on nitric oxide (NO) - an endothelial product mediating the vessel relaxation. In papers 2. and 3. selected method was cuffing the arteries and post-occlusion measurement of the time of peak reperfusion (Tmax). Results lower than 45 seconds were considered NEF indicator, whereas the ones equal to and higher than that value were defined as ED. The occlusion was placed on wrist, affecting ulnar and radial arteries. Alternative method - peripheral artery tonometry (PAT) was used in article 1. to establish RHI values, with NEF/ED cut off point equal to the one in 2. and 3. Additional test used in this study was fasting measurement of serum levels of endothelin-1 (ET-1) and NO in morning hours $(8 \mathrm{am}-10 \mathrm{am})$ through enzyme-linked immunosorbent assay (ELISA). ET-1/NO ratio is standard index of endothelial dysfunction - represented with elevation of ET-1 level and lowering NO level. Patients characteristics are presented in the Table 3.

Table 3. Articles concerning the differences of miRNA levels in endothelial dysfunction and physiology

\begin{tabular}{|c|c|c|c|c|c|}
\hline Article & Group & Number of Patients & Age (years) & Sex (\% of male) & $\begin{array}{l}\text { BMI-z } \\
{ }^{*} \mathrm{BMI}\end{array}$ \\
\hline \multirow{2}{*}{1.} & $C G^{1}$ & $\mathrm{n}=10$ & $12-18$ & 100 & $\begin{array}{c}\text { Pre }{ }^{*} 23.05 \pm 0.46 \\
\text { Post } \\
* 23.01 \pm 0.50\end{array}$ \\
\hline & $\mathrm{EG}^{1}$ & $\mathrm{n}=37$ & $12-18$ & 100 & $\begin{array}{c}\text { Pre }{ }^{* 33.48} \pm 3.54 \\
\text { Post } \\
* 29.63 \pm 3.16\end{array}$ \\
\hline \multirow{2}{*}{2.} & NEF & $\mathrm{n}=25$ & $7.59 \pm 1.26$ & 70.4 & $1.69 \pm 0.62$ \\
\hline & ED & $\mathrm{n}=35$ & $8.41 \pm 1.20$ & 63.8 & $2.00 \pm 0.68$ \\
\hline \multirow{3}{*}{3.} & $\mathrm{OB}_{\mathrm{NEF}}$ & $n=23$ & $7.6 \pm 2.6$ & 56.5 & $1.74 \pm 0.28$ \\
\hline & $\mathrm{OB}_{\mathrm{ED}}$ & $\mathrm{n}=20$ & $7.7 \pm 2.8$ & 60 & $1.76 \pm 0.31$ \\
\hline & CG & $\mathrm{n}=26$ & $7.3 \pm 2.2$ & 58 & $1.08 \pm 0.21$ \\
\hline
\end{tabular}

\footnotetext{
Abbreviations: CG, control group; ED, endothelial dysfunction; EG, experimental group; NEF, normal endothelial function; $\mathrm{OBNEF}_{\mathrm{N}}$ obese with normal endothelial function; $\mathrm{OB}_{\mathrm{ED}}$, obese with endothelial dysfunction; BMI, body mass index; BMI-z, body mass index Z-score;
}

Footnote: ${ }^{1}$-Total number of patients in this study was 67 subjects, but due to various reasons 7 subjects were excluded before the intervention, and the next 13 subjects during the intervention phase of experiment

Study 1 . is quazi-randomized experiment concentrating on quantification of changes in blood markers (including miR-126) and anthropometric parameters linked to the endothelial functionality after 6 weeks of dietary and physical training intervention in population of obese (EG) and healthy (CG) male adolescents (12-18 yo) with no regular exercise routines.

Study 2. investigated the differences in levels of miRNAs previously linked to the cardiomyopathy between two groups (NEF, ED) of obese children (BMI-z $\geq 1,65$ ), later followed by 
the same procedure in two groups (NEF, ED) of total 10 non-obese children (characteristics not shown in Table 3. due to lack of information in the article). RHI was significantly different in NEF group (26.8 $\pm 11.4 \mathrm{~s}$ ) compared to ED group (62.4 $\pm 15.9 \mathrm{~s})$, with no distinction in systolic and diastolic blood pressure. Collected data was subsequently used to predict gene targets and their network via target prediction programs.

Population of study 3. consisted of children affected by two diseases, which separately contribute to the development of ED - obesity and obstructive sleep apnea (OSA). For the purpose of this paper, focus was put only on obese children (both NEF and ED) and control group (CG). Plasmaderived extracellular microvesicles were obtained from the subjects of each group and then applied to the human primary endothelial cells. Influence of EV on endothelial monolayer was measured with electric cell-substrate impedance sensing (ECIS) instrument, providing information concerning cell resistance, locomotion and changes in cytoskeleton and morphology. EVs were also injected into murine circulation, followed by the measurement of Tmax. Uptake and interactions of EVs and cells were verified with fluorescent dye. MiRNA content of EVs was investigated using microarrays and further validated with RT-PCR (reverse transcription polymerase chain reaction).

\subsection{Non-alcoholic fatty liver disease}

Articles 4. and 5. examined the existence of relations between miRNAs levels and serum levels of clinically approved markers of hepatic steatosis: aspartat-aminotransferase, alaninaminotransferase (both articles), glutamat-pyruvat-transaminase (only article 5.) (respectively: AST, ALT, GGT) as well as BMI and BMI-z scores in obese children with NAFLD (NAFLD) compared to control group (CG) of lean children (article 4.) or in three pediatric cohorts from hospitals in Germany (GC), Italy (IC), Slovenia (SC). Additional marker adopted in study 5. was cytokeratin 18 (CK18) measured in serum or plasma using ELISA. In both studies severity of liver steatosis was graded using ultrasonography into scale: undetectable/mild/diffuse (article 4.) or no-steatosis/grade I/grade II/grade III (article 5.). Characteristics of patients are presented below in Table 4.

Table 4. Parameters of patients in studies concerning NAFLD

\begin{tabular}{cccccc}
\hline Article & Group & $\begin{array}{c}\text { Number of } \\
\text { Patients }\end{array}$ & Age (years) & $\begin{array}{c}\text { Sex (\% of } \\
\text { male) }\end{array}$ & $\begin{array}{c}\text { BMI-z } \\
{ }^{*} \text { BMI }\end{array}$ \\
\hline \multirow{2}{*}{4.} & NAFLD & $\mathrm{n}=20$ & $13.2 \pm 3.1$ & 70 & $* 34.7 \pm 10.2$ \\
\cline { 2 - 6 } & $\mathrm{CG}$ & $\mathrm{n}=10$ & $13.8 \pm 2.1$ & 40 & ${ }^{*} 20.11 \pm 2.5$ \\
\hline \multirow{3}{*}{5.} & $\mathrm{GC}$ & $\mathrm{n}=71$ & $11.53 \pm 1.29$ & 73.2 & $2.96 \pm 0.64$ \\
\cline { 2 - 6 } & $\mathrm{IC}$ & $\mathrm{n}=45$ & $9.60 \pm 2.11$ & 68.9 & $3.57 \pm 1.16$ \\
\cline { 2 - 6 } & $\mathrm{SC}$ & $\mathrm{n}=31$ & $7.53 \pm 1.47$ & 38,7 & $3.66 \pm 0.88$
\end{tabular}

Abbreviations: BMI - body mass index; BMI-z - body mass index Z-score; CG, control group; GC, German cohort; IC, Italian cohort; NAFLD, non-alcoholic fatty liver disease; SC, Slovenian cohort;

Panel of miRNAs chosen for analysis in article 4. was selected based on their known role in pathogenesis of NAFLD or relation between their levels and NAFLD occurrence in adult patients, as proved in previous studies. Ribozol reagent and RNeasy columns were used in purification of miRNAs. Purified material was then reversely transcribed and cDNA transcripts (after 40-fold dilution) were used to quantify miRNA levels through PCR (polymerase chain reaction). The average BMI percentile for NAFLD group was $99,2 \%$, for CG it was $57,6 \%$. ALT levels of NAFLD patients were elevated in $18 / 20$ subjects, AST in 5/20. In 17 of them USG procedure detected diffuse steatosis, in 2 mild steatosis, in 1 there was no steatosis found.

German and Italian cohorts from study 5. were diagnosed with NAFLD using ultrasonography, in contrast to Slovenian cohort, where no USG examination was performed. Data concerning anthropometric measures and previously mentioned fat metabolism markers have been collected in each cohort (fasting blood samples collected in the morning hours, GGT was not measured in SC). 
Significantly more children have been diagnosed with NAFLD in IC $(72,5 \%)$ than GC $(29,6 \%)$, probably due to specificity of recruitment center - subjects in IC were referred there by pediatricians and outpatients clinics. Isolation of miRNAs was carried out using a miRNeasy Mini Kit, followed by further reverse transcription (miScript Reverse Transcription Kit) and qPCR (quantitative PCR) for miR-122 (miScript SYBR Green PCR Kit). Results were then normalized and compared to biochemical and anthropometric parameters.

\subsection{Type 2 diabetes mellitus}

The goal of study 6 . was the comparative analysis of miRNA levels in pediatric group of obese/overweight/non-obese (OB/OW/CG) children; adult group of type 2 diabetes/normal glucose tolerance (T2DM/NGT) patients and animal model group of obese/diabetic (ob/db) mice. First stage was miRNA profiling of $9 \mathrm{OB}$ and $9 \mathrm{CG}$ patients, validated further in full-size final pediatric groups (stage 2.) and T2DM/NGT adults. MiRNAs chosen based on the results of this experiment were then transfected using lentivirus into human preadipocyte, murine beta-cell (MIN6) and myoblast (C2C12) cultures in order to examine their influence on respectively adipocytes cell proliferation, insulin secretion and glucose intake. Obesity and overweight in children was defined with BMI standard deviations (SDs), according to WHO Child Growth Standards (CGS). Thresholds for groups depending on age are presented below (Table 5.). Cut-off point for T2DM identification in patient was fasting plasma glucose (FPG) $>7.0 \mathrm{mmol} / \mathrm{L}$. Information regarding FPG as well as age, serum triglyceride and cholesterol levels of subjects were collected from hospitals.

Table 5. Criteria of obesity grading in study 6 .

\begin{tabular}{|c|c|c|}
\hline Group $\backslash$ Age & under 60 months of age & over 60 months of age \\
\hline CG & $\begin{array}{c}\mathrm{BMI} \leq 2 \text { SDs over WHO CGS } \\
\text { median }\end{array}$ & $\begin{array}{c}\mathrm{BMI} \leq 1 \text { SDs over WHO CGS } \\
\text { median }\end{array}$ \\
\hline OW & $\begin{array}{c}\text { BMI > } 2 \text { SDs over WHO CGS } \\
\text { median }\end{array}$ & $\begin{array}{c}\text { BMI > } 1 \text { SDs over WHO CGS } \\
\text { median }\end{array}$ \\
\hline OB & $\begin{array}{c}\text { BMI > } 3 \text { SDs over WHO CGS } \\
\text { median }\end{array}$ & $\begin{array}{c}\text { BMI }>2 \text { SDs over WHO CGS } \\
\text { median }\end{array}$ \\
\hline
\end{tabular}

Abbreviations: CG, non-obese; $\mathrm{OB}$, obese; OW, overweight

Study 7. was conducted in an answer to the results of study 6. Serum levels of three selected miRNA molecules, as well as the betatrophin were measured and compared between groups of nonobese (5th to 85th BMI percentile), obese ( $>$ 95th percentile) and diabetic children (based on previous results of FPG, blood glucose, OGTT test or HbA1c). Venous blood samples for the purpose of measurement of $\mathrm{HbA} 1 \mathrm{c} \%$, betatrophin, cholesterol, glucose and miRNAs relative expression levels were collected after overnight fasting. Correlations of miRNAs expression, betatrophin and other parameters were tested by Pearson correlations coefficient (significance: $p<0.05$ ). ROC of miRNAs and serum betatrophin were made to measure the differentiating potential between the groups.

Characteristics of patients in both studies are presented in Table 6 . 
Table 6. Characteristics of groups examined in Study 6. and 7.

\begin{tabular}{|c|c|c|c|c|c|}
\hline Article & Group & Number of Patients & $\begin{array}{l}\text { Age (months) } \\
* \text { (years) }\end{array}$ & Sex ( $\%$ of male $)$ & $\begin{array}{c}\text { BMI } \\
{ }^{*} \text { BMI } \\
\text { percentile }\end{array}$ \\
\hline \multirow{5}{*}{3.} & OB & $\mathrm{n}=100$ & $61.0 \pm 10.4$ & 48,5 & $20.3 \pm 2.20$ \\
\hline & OW & $\mathrm{n}=106$ & $59.6 \pm 11.0$ & 47,2 & $17.4 \pm 0.60$ \\
\hline & CG & $\mathrm{n}=146$ & $60.4 \pm 11.1$ & 40,4 & $15.1 \pm 1.06$ \\
\hline & $\mathrm{T} 2 \mathrm{DM}$ & $\mathrm{n}=101$ & $* 57.5 \pm 12.2$ & NS & $26.8 \pm 4.19$ \\
\hline & NGT & $\mathrm{n}=82$ & ${ }^{*} 49.3 \pm 7.73$ & NS & $24.3 \pm 3.22$ \\
\hline \multirow{3}{*}{4.} & CG & $\mathrm{n}=50$ & $* 9.31 \pm 1.47$ & 62 & $81.0 \pm 1.2$ \\
\hline & OB & $\mathrm{n}=35$ & $* 9 \pm 1.77$ & 77 & $96.8 \pm 1.6$ \\
\hline & $\mathrm{t} 2 \mathrm{DM}$ & $\mathrm{n}=35$ & $* 9.59 \pm 1.40$ & 63 & $96.7 \pm 1.4$ \\
\hline
\end{tabular}

Abbreviations: CG, non-obese children; NGT, normal glucose tolerance adults; NS, not specified; OB, obese children; OW, overweight children; T2DM, diabetic adults; t2DM, diabetic children

\subsection{Metabolic Syndrome}

As with the obesity, we can observe the increase of metabolic syndrome (MetS) prevalence worldwide. This term represents the cluster of metabolic changes, which stem directly from longterm positive energy balance. These alterations include obesity, followed by hypertension, insulin resistance and atherogenic dyslipidemia [20]. Recently the study on 250 adolescents (study 8.) investigated the relation between miRNA molecules and adipokines, specifically adiponectin and leptin, as the latter are known to play important role in regulating and maintaining the metabolic homeostasis, thus their dysregulation is a strong evidence of developing metabolic disorders. Patients were categorized based on their obesity scores into three groups: normal (NW), overweight (OW) and obese $(\mathrm{OB})$. Their body parameters, including those connected with MetS, are presented below in Table 7.

Table 7. Characteristic of patients in study 8.

\begin{tabular}{|c|c|c|c|c|}
\hline \multicolumn{2}{|r|}{ Parameters } & $\mathrm{NW}(\mathrm{n}=50)$ & $\mathrm{OW}(\mathrm{n}=100)$ & $\mathrm{OB}(\mathrm{n}=100)$ \\
\hline \multicolumn{2}{|r|}{ Age (years) } & $13.8 \pm 2.88$ & $13.85 \pm 2.89$ & $13.87 \pm 2.91$ \\
\hline \multicolumn{2}{|c|}{ Gender ( $\%$ male) } & 56 & 51 & 71 \\
\hline & BMI & $17.4 \pm 4.3$ & $21.9 \pm 5.7$ & $26.7 \pm 8.2$ \\
\hline \multirow{3}{*}{$\mathrm{BP}(\%)$} & Normotensive & 50 & 79.0 & 42.8 \\
\hline & Pre-hypertensive & 0 & 15.8 & 22.0 \\
\hline & Hypertensive & 0 & 5.2 & 35.2 \\
\hline \multicolumn{2}{|c|}{$\mathrm{FBG}(\mathrm{mmol} / \mathrm{L})$} & $4.1 \pm 0.3$ & $5.3 \pm 0.8$ & $5.9 \pm 1.6$ \\
\hline \multicolumn{2}{|c|}{ Insulin (mU/L) } & 6.3 & $9.4(6.4 \pm 13.71)$ & $14.5(7.2 \pm 19.7)$ \\
\hline \multicolumn{2}{|r|}{ HOMA-IR } & $\begin{array}{c}1.48 \\
(0.84 \pm 1.95)\end{array}$ & $\begin{array}{c}2.93 \\
(1.86 \pm 4.81)\end{array}$ & $\begin{array}{c}4.65 \\
(2.48 \pm 6.81)\end{array}$ \\
\hline \multicolumn{2}{|c|}{ C-peptide (ng/mL) } & $0.63 \pm 0.43$ & $1.65 \pm 1.2$ & $1.78 \pm 1.4$ \\
\hline \multicolumn{2}{|r|}{ TG (mg/mL) } & $0.58 \pm 0.24$ & $1.38 \pm 0.63$ & $2.58 \pm 0.94$ \\
\hline \multicolumn{2}{|c|}{ HDL-C (mg/mL) } & $1.7 \pm 0.34$ & $1.23 \pm 0.18$ & $1.13 \pm 0.28$ \\
\hline
\end{tabular}




\begin{tabular}{cccc}
\hline Parameters & NW $(\mathrm{n}=50)$ & OW $(\mathrm{n}=100)$ & OB $(\mathrm{n}=100)$ \\
\hline Age (years) & $13.8 \pm 2.88$ & $13.85 \pm 2.89$ & $13.87 \pm 2.91$ \\
\hline LDL-C $(\mathrm{mg} / \mathrm{mL})$ & $1.8 \pm 0.78$ & $2.31 \pm 0.74$ & $3.85 \pm 0.72$
\end{tabular}

Abbreviations: BMI, body mass index; BP, blood pressure; FBG, fasting blood glucose; TG, triglycerides; HDLC, high-density lipoprotein cholesterol; LDL-C, low-density lipoprotein cholesterol; HOMA-IR, homeostatic model assessment of insulin resistance

Plasma samples collected from patients were used for isolation of total RNA, which in turn was then subject to RT-PCR using ready-made solutions for miR-142-3p, miR-140-5p,miR-222,miR-143, miR-130, miR-532-5p, miR-423-5p, miR-520c-3p, miR-146a, and miR-15a. Real time qPCR, as well as relative quantification using $2-\Delta \Delta \mathrm{CT}$ method were performed basing on obtained previously cDNA. Adipokines levels were measured using specific ELISA kits.

\subsection{Atherosclerosis}

Relation between BMI, miRNA levels (both circulatory - EVs - and tissue - visceral adipose tissue; VAT levels) and cholesterol efflux capacity of THP-1 derived macrophages was examined in study 9., based on population of obese (BMI $>25 \mathrm{~kg} / \mathrm{m} 2)$ and non-obese (BMI $\leq 25 \mathrm{~kg} / \mathrm{m} 2$ ) adolescents (1219 yo). Cholesterol efflux capacity reduction leads to creation of foam cells, thus being crucial for the development of atherosclerosis. Lipoprotein concentrations were measured using nuclear magnetic resonance (NMR), followed by calculation of the lipoprotein insulin resistance index (LP-IR) based on HOMA-IR data from Multi-Ethnic Study of Atherosclerosis (MESA). Adipocyte-derived EVs were obtained from serum of female subgroup (chosen as representative of cohort) using EoxQuick Precipitation Solution, with further extraction of total RNA (SeraMir Exosome RNA Amplification Kit), labeling via biotin and hybridization to Affymetrix GeneChip microRNA 4.0 arrays. Each participant has undergone the bariatric surgery after 2 weeks of protein-saving diet $(1000 \mathrm{kcal} /$ day, 50 - $60 \mathrm{~g}$ protein) and pre-intervention overnight fasting. VAT collected during this process served as the miRNA source. EVs (after dilution in fetal calf serum (FCS) to $1 \mu \mathrm{g} / \mathrm{mL}$ or $3 \mu \mathrm{g} / \mathrm{mL}$ ) were applied on THP-1 macrophages alone or with $5 \mu \mathrm{g} / \mathrm{mL}$ 1,1'-dioctadecyl-3,3,3',3'-tetramethylin docarbocyaninet (DiI)-oxLDL, as well as $5 \mu \mathrm{g} / \mathrm{mL}$ DiI-oxLDL alone, to examine its effect on THP-1 cholesterol intake. THP-1 macrophages plated in well plates $(106$ cells $/ \mathrm{mL})$ were also treated with 1 $\mu \mathrm{g} / \mathrm{mL}$ or $3 \mu \mathrm{g} / \mathrm{mL}$ solutions of adipocyte-derived EVs and separately supplemented RPMI 1640 medium in order to assess the cholesterol efflux using Amplex Red Cholesterol Assay kit. These cells were then used for total RNA isolation, and after reverse transcription and PCR amplification of acquired cDNA (using primers for ABCA1, ABCG1, CYP27A1, PPAR $\gamma$, and LXR $\alpha$ ), quantitative analysis of expressed genes was conducted with SYBR Green Reagent Kit. Patients' characteristics are presented in Table 8.

Table 8. Parameters of patients included in Article 9.

\begin{tabular}{|c|c|c|c|c|}
\hline Article & Number of Patients & $\begin{array}{l}\text { Age in years; } \\
\text { median (IQR) }\end{array}$ & Sex (\% of male) & $\begin{array}{c}\text { BMI; } \\
\text { median (IQR) }{ }^{1}\end{array}$ \\
\hline 9. & $n=93$ & $17 ; 3^{1}$ & 23,7 & $45.2 ; 13.2^{1}$ \\
\hline
\end{tabular}

\section{Discussion}

Facing the newest progress in techniques of isolating, sequencing and quantification of nucleic acids (in that case miRNA) from various biological materials, we begin to understand their crucial role in both genetic and epigenetic mechanisms regulating functioning of nearly every process in human body. Observing changes of miRNA levels in various physiological and pathological conditions creates possibilities to establish new ways of disease diagnosis, treatment, as well as the comorbidities and complications prediction. 
Examined miRNAs, level changes, as well as their significance and area under receiver-operator curve (AUC) score are presented in Table 9.

Table 9. Summary of studies results

\begin{tabular}{|c|c|c|c|c|c|c|}
\hline $\begin{array}{l}\text { Article } \\
\text { no. }\end{array}$ & Comorbidity & Molecule & Compared groups & $\begin{array}{l}\text { Status (fold } \\
\text { change) }\end{array}$ & $\begin{array}{l}\text { Significance } \\
\text { (p- value) }\end{array}$ & AUC \\
\hline \multirow{2}{*}{1.} & \multirow{2}{*}{ ED } & \multirow{2}{*}{ miR-126 } & $\begin{array}{l}\text { Pre-CG vs } \\
\text { Pre-EG }\end{array}$ & UE & $<0.01$ & - \\
\hline & & & $\begin{array}{l}\text { Pre-EG vs } \\
\text { Post-EG }\end{array}$ & $\mathrm{OE}$ & $<0.01$ & - \\
\hline \multirow{3}{*}{2.} & \multirow{3}{*}{ ED } & miR-125a-5p & \multirow{3}{*}{ ED vs NEF } & $\begin{array}{c}-1.33 \pm 0.11^{2} \\
(-1.27 \pm 0.12)^{3}\end{array}$ & $\begin{array}{c}0.02 \\
(0.01)^{3}\end{array}$ & - \\
\hline & & $\operatorname{miR}-342-3 p$ & & $\begin{array}{c}-1.41 \pm 0.08^{2} \\
(-1.22 \pm 0.06)^{3}\end{array}$ & $\begin{array}{c}0.03 \\
(0.02)^{3}\end{array}$ & - \\
\hline & & miR-365b-3p & & $\begin{array}{c}1.41 \pm 0.14^{2} \\
(1.52 \pm 0.23)^{3}\end{array}$ & $\begin{array}{c}0.004 \\
(0.001)^{3}\end{array}$ & - \\
\hline \multirow{5}{*}{3.} & \multirow{5}{*}{ ED } & miR-16-5p & \multirow{5}{*}{ ED vs NEF } & -3.18 & $<0.0001$ & - \\
\hline & & $\operatorname{miR}-451 \mathrm{a}$ & & -3.74 & $<0.0001$ & - \\
\hline & & $\operatorname{miR}-5100$ & & -1.65 & $<0.01$ & - \\
\hline & & miR-630 & & -4.11 & $<0.0001$ & - \\
\hline & & $\operatorname{miR}-4665-3 p$ & & 2.35 & $<0.01$ & - \\
\hline \multirow{19}{*}{4.} & \multirow{19}{*}{ NAFLD } & miR-15b-5p & \multirow{19}{*}{ NAFLD vs CG } & 3.42 & 0.0004 & 0.8639 \\
\hline & & miR-199a-5p & & 17.18 & $<0.0001$ & $0.9750^{1}$ \\
\hline & & $\operatorname{miR}-222-3 p$ & & 2.14 & $<0.0001$ & $0.9167^{1}$ \\
\hline & & $\operatorname{miR}-223-5 p$ & & 6.72 & $<0.0001$ & $0.9611^{1}$ \\
\hline & & $\operatorname{miR}-34 a-5 p$ & & 3.29 & 0.0009 & 0.8778 \\
\hline & & $\operatorname{miR}-122-5 p$ & & 12.48 & $<0.0001$ & $0.9833^{1}$ \\
\hline & & $\operatorname{miR}-23 a-5 p$ & & 5.3 & $<0.0001$ & $0.9708^{1}$ \\
\hline & & $\operatorname{miR}-27 b-3 p$ & & 6.74 & $<0.0001$ & $0.9611^{1}$ \\
\hline & & miR-21-5p & & 4.89 & $<0.0001$ & $0.9813^{1}$ \\
\hline & & $\operatorname{miR}-34 a-5 p$ & & 5.09 & $<0.0001$ & $0.9361^{1}$ \\
\hline & & miR-451-5p & & 1.54 & 0.0404 & 0.7667 \\
\hline & & miR-192-5p & & 3.78 & $<0.0001$ & $0.9472^{1}$ \\
\hline & & miR-16-5p & & 1.56 & 0.0064 & 0.8000 \\
\hline & & miR-29a-3p & & 2.81 & $<0.0001$ & $0.9444^{1}$ \\
\hline & & miR-150-5p & & 1.79 & 0.0006 & 0.8861 \\
\hline & & $\operatorname{miR}-214-3 p$ & & 2.73 & 0.0213 & 0.7684 \\
\hline & & miR-375 & & 1.04 & 0.8570 & 0.6199 \\
\hline & & miR-155-5p & & 2.63 & 0.0023 & 0.8875 \\
\hline & & miR-191-5p & & 7.21 & $<0.0001$ & $0.9605^{1}$ \\
\hline
\end{tabular}




\begin{tabular}{|c|c|c|c|c|c|c|}
\hline \multicolumn{4}{|c|}{$\operatorname{miR}-103 a-5 p$} & \multirow{2}{*}{$\frac{3.38}{\mathrm{OE}}$} & \multirow{2}{*}{$\begin{array}{c}<0.0001 \\
<0.05\end{array}$} & \multirow{2}{*}{$\begin{array}{c}0.9474^{1} \\
0.77\end{array}$} \\
\hline 5 & NIA DI & mip 122 & NAFLD vs NN (GC) & & & \\
\hline J. & 1 & $11010-122$ & NAFLD vs NN (IC) & NS & $>0.05$ & 0.54 \\
\hline \multirow{6}{*}{6.} & \multirow{6}{*}{$\mathrm{T} 2 \mathrm{DM}$} & \multirow{2}{*}{ miR-15b } & OB vs CG & $\mathrm{OE}$ & $<0.01$ & - \\
\hline & & & T2DM vs NGT & $\mathrm{OE}$ & $<0.01$ & $0.969^{1}$ \\
\hline & & \multirow{2}{*}{ miR-146b } & OB vs CG & $\mathrm{OE}$ & $<0.01$ & - \\
\hline & & & T2DM vs NGT & $\mathrm{OE}$ & $<0.01$ & 0.882 \\
\hline & & \multirow{2}{*}{$\operatorname{miR}-486$} & OB vs CG & $\mathrm{OE}$ & $<0.01$ & - \\
\hline & & & T2DM vs NGT & $\mathrm{OE}$ & $<0.01$ & $0.923^{1}$ \\
\hline \multirow{9}{*}{7.} & \multirow{9}{*}{ T2DM } & \multirow{3}{*}{ miR-486R } & OB vs CG & $\mathrm{OE}$ & 0.003 & - \\
\hline & & & t2DM vs CG & $\mathrm{OE}$ & $<0.001$ & - \\
\hline & & & t2DM vs OB & $\mathrm{OE}$ & 0.001 & 0.61 \\
\hline & & \multirow{3}{*}{ miR-146bR } & OB vs CG & $\mathrm{OE}$ & $<0.001$ & - \\
\hline & & & t2DM vs CG & $\mathrm{OE}$ & $<0.001$ & - \\
\hline & & & t2DM vs OB & $\mathrm{OE}$ & $<0.001$ & 0.54 \\
\hline & & \multirow{3}{*}{ miR-15bR } & OB vs CG & $\mathrm{OE}$ & $<0.001$ & - \\
\hline & & & t2DM vs CG & $\mathrm{OE}$ & $<0.001$ & - \\
\hline & & & t2DM vs OB & $\mathrm{OE}$ & $<0.001$ & 0.62 \\
\hline \multirow{16}{*}{8.} & \multirow{16}{*}{ MetS } & \multirow{2}{*}{ miR-142-3p } & OW vs CG & $\mathrm{OE}$ & $<0.01$ & - \\
\hline & & & OB vs CG & $\mathrm{OE}$ & $<0.001$ & - \\
\hline & & \multirow{2}{*}{ miR-140-5p } & OW vs CG & $\mathrm{OE}$ & $<0.01$ & - \\
\hline & & & OB vs CG & $\mathrm{OE}$ & $<0.001$ & - \\
\hline & & \multirow{2}{*}{ miR-222 } & OW vs CG & $\mathrm{OE}$ & $<0.01$ & - \\
\hline & & & OB vs CG & $\mathrm{OE}$ & $<0.001$ & - \\
\hline & & \multirow{2}{*}{ miR-143 } & OW vs CG & $\mathrm{OE}$ & $<0.01$ & - \\
\hline & & & OB vs CG & $\mathrm{OE}$ & $<0.001$ & - \\
\hline & & \multirow{2}{*}{ miR-130 } & OW vs CG & $\mathrm{OE}$ & $<0.01$ & - \\
\hline & & & OB vs CG & $\mathrm{OE}$ & $<0.001$ & - \\
\hline & & \multirow{2}{*}{ miR-532-5p } & OW vs CG & UE & $<0.01$ & - \\
\hline & & & OB vs CG & $\mathrm{UE}$ & $<0.001$ & - \\
\hline & & \multirow{2}{*}{ miR-423-5p } & OW vs CG & $\mathrm{UE}$ & $<0.01$ & - \\
\hline & & & OB vs CG & $\mathrm{UE}$ & $<0.001$ & - \\
\hline & & \multirow{2}{*}{$\operatorname{miR}-520 c-3 p$} & OW vs CG & $\mathrm{UE}$ & $<0.01$ & - \\
\hline & & & OB vs CG & UE & $<0.001$ & - \\
\hline
\end{tabular}




\begin{tabular}{|c|c|c|c|c|c|c|}
\hline & & \multirow{2}{*}{ miR-146a } & OW vs CG & UE & $<0.01$ & - \\
\hline & & & OB vs CG & UE & $<0.001$ & - \\
\hline & & \multirow{2}{*}{ miR-15a } & OW vs CG & UE & $<0.01$ & - \\
\hline & & & OB vs CG & UE & $<0.001$ & - \\
\hline \multirow{6}{*}{9.} & \multirow{6}{*}{ AS } & miR-3129-5p & \multirow{6}{*}{ HCE vs LCE } & $\mathrm{OE}$ & $<0.01$ & - \\
\hline & & miR-206 & & $\mathrm{OE}$ & $<0.01$ & - \\
\hline & & $\operatorname{miR}-9-5 p$ & & UE & $<0.01$ & - \\
\hline & & miR-320d & & UE & $<0.01$ & - \\
\hline & & miR-301-5p & & $\mathrm{UE}$ & $<0.01$ & - \\
\hline & & miR-155-5p & & UE & $<0.01$ & - \\
\hline
\end{tabular}

Abbreviations: AUC, area under receiver-operator curve; CG, control group; ED, endothelial dysfunction; GC, German cohort; HCE, high cholesterol efflux; IC, Italian cohort; LCE, low cholesterol efflux; MetS, metabolic syndrome; miR, miRNA; NAFLD, non-alcoholic fatty liver disease; NEF, normal endothelial function; NGT, normal glucose tolerance adults; NN, non-NAFLD; NS, not specified; OB, obese children; OE, overexpressed;

Post-EG, post-intervention experimental group; Pre-CG, pre-intervention control group; Pre-EG, preintervention experimental group; T2DM, diabetic adults; t2DM, diabetic children UE, under-expressed

Footnotes: ${ }^{1}$ - significant AUC result $(>0.9) ;^{2}$ - cardiovascular arrays; ${ }^{3}$ - qRT-PCR (quantitative reverse transcription polymerase chain reaction) validation;

\subsection{Endothelial dysfunction}

Condition of endothelium as a whole can be inspected via levels of endothelial products, like $\mathrm{NO}$ and ET-1, their ratio (NO/ET-1) or through functional test - RHI measurement, whose score is dependent on endothelial reaction engaging NO. Some miRNAs have established role in physiology of endothelium, angiogenesis, although they have not been yet applied clinically as the markers of endothelial dysfunction.

Physical activity is one of the factors contributing to healthy endothelium. MiRNA-126 is widely regarded to be linked with functionality of this tissue and as such was chosen for the subject of study 1., which examined possible role of this molecule in mechanism of ED renewal during 6 weeks of interventional lifestyle program (dietary and exercise routine change) in obese adolescent population. Intervention resulted in increased quality of endothelial condition, associated with statistically significant rise of RHI and NO/ET-1 parameters (see Table 10). Simultaneously miRNA-126 levels also increased, with positive correlation to BMI decrease and growth of RHI and NO/ET-1 (respectively $\mathrm{r}=0.50, \mathrm{P}<0.05 ; \mathrm{r}=0.69, \mathrm{P}<0.05 ; \mathrm{r}=0.68, \mathrm{P}<0.05$ ).

Table 10. Differences in marker levels before and after the intervention in study 1.

\begin{tabular}{cccc}
\hline Marker & miR-126 & RHI & NO/ET-1 \\
\hline Pre-EG & $0.51 \pm 0.27$ & $1.43 \pm 0.35$ & $1.73 \pm 0.51$ \\
\hline Post-EG & $0.67 \pm 0.21$ & $1.67 \pm 0.36$ & $2.72 \pm 0.92$ \\
\hline $\begin{array}{c}P \text { - value } \\
\text { (Pre vs } \\
\text { Post) }\end{array}$ & $<0.01$ & $<0.01$ & $<0.01$ \\
\hline
\end{tabular}

Abbreviations: ET-1, endothelin-1; miR, miRNA; NO, nitric oxide; Post-EG, post-intervention experimental group; Pre-EG, pre-intervention experimental group; RHI, reactive hyperemia index; 
Method used for measurement of RHI - PAH - is highly dependent on age and sex of subjects [21], thus the uniformity of groups in this regard is highly required. Unfortunately, in this study the patients' age parameter had a wide range (12-18 years), hence the RHI results might be unreliable.

The goal of study 2. was to establish differences in expression of miRNAs specific for CVD in groups of NEF and ED children using microarray assay, with further validation of results using qRTPCR for three miRNAs whose expression was significantly different between groups. The procedure was repeated for groups of non-obese ED and NEF children, to rule out the influence of BMI-z score. MiRNA profile in these groups was similar to the one in obese groups (see Table 11).

Table 11. Comparison of results from microarray and qRT-PCR assays in study 2.

\begin{tabular}{ccccc}
\hline \multicolumn{2}{c}{ Molecule } & miR-365b-3p & miR-125a-5p & miR-342-3p \\
\hline \multirow{2}{*}{ MICROARRAY } & Fold change & $1.41 \pm 0.14$ & $-1.33 \pm 0.11$ & $-1.41 \pm 0.08$ \\
\cline { 2 - 5 } & $P$ - value & 0.004 & 0.02 & 0.03 \\
\hline \multirow{2}{*}{ qRT-PCR } & Fold change & $1.52 \pm 0.23$ & $-1.27 \pm 0.12$ & $-1.22 \pm 0.06$ \\
\cline { 2 - 5 } & $P$ - value & 0.001 & 0.01 & 0.02
\end{tabular}

Abbreviations: miR, miRNA; qRT-PCR, quantitative reverse transcription polymerase chain reaction

Gene mapping has revealed putative targets of these three molecules (respectively: 1194; 683; 679 genes, and 31 genes mutual for all three), involved in TGF- $\beta$ signaling, cytokine-cytokine receptor interactions and activin receptor-like kinase pathways in cardiac myocytes, included in MED13 and MED14 mediator complexes. This study has suggested the possible value of forementioned three miRNA molecules as endothelial dysfunction indicators, but unfortunately they seem to be unrelated to obesity's involvement in development of this comorbidity.

Study 3. identified 4 miRNA molecules significantly underexpressed and one overexpressed in OBED children when compared to OBNEF group (see Table 12). EV obtained from ED patients disrupted integrity of endothelial cell culture membrane and significantly $(\mathrm{P}<0.001)$ reduced expression of mRNA coding endothelial NO synthase (eNOS). Injection of EVs derived from OBED subjects into murine circulation prolonged Tmax significantly $(\mathrm{P}<0.001)$ in juxtaposition to the effects of injection of both CG- and OBNEF-derived EVs.

Table 12. Change of miRNA expression between ED and NEF children in study 3.

\begin{tabular}{ccc}
\hline Molecule & Fold change & $P$ - value \\
\hline miR-16-5p & -3.18 & $<0.0001$ \\
\hline miR-451a & -3.74 & $<0.0001$ \\
\hline miR-5100 & -1.65 & $<0.01$ \\
\hline miR-630 & -4.11 & $<0.0001$ \\
\hline miR-4665-3p & 2.35 & $<0.01$ \\
\hline
\end{tabular}

Abbreviations: miR, miRNA

MiRNA-630 was chosen for further examination due to its highest fold change parameter. Endothelial monolayer culture was treated with EVs transfected with miR-630 mimic, inhibitor or mixture of two. Mimic induced restoration of the culture from ED cells, while in NEF cells culture (influenced by the inhibitor) the resistance and ZO-1 distribution were altered. Gene targets specific for miRNA-630 are engaged in 10 pathways, among them the ones involved in NRF2-mediated oxidative stress responses, AMP kinase, and tight junction signaling.

The value of results of this study can be limited due to relatively small size of examined group, although the direct influence of miR-630 administration via EVs in cell culture and animal model on endothelium creates promising therapeutic option for ED treatment. 


\subsection{Non-alcoholic fatty liver disease}

Diagnosis of NAFLD is based on rating the function and condition of liver with liver-associated enzymes - ALT, AST, GGT, or through biopsy, which provides information concerning steatosis and fibrosis of this organ. Proper identification scheme for this disease is highly needed considering its rising occurrence. Recently many studies concentrated on said assessment methods $[22,23]$ although the use of miRNA markers seems to be yet out of their scope of interest.

Results of study 4. presented a panel of 16 (out of 20 tested) miRNAs that were significantly (P $<0.05$; $>2$-fold change) overexpressed in children with NAFLD compared to healthy controls. Discriminating potential was examined using receiver-operator curves (ROC), providing AUC parameter. 12 molecules had AUC greater than 0.9, although the highest results in this regard scored miR-122-5p (0.9833), miR-21-5p (0.9813), miR-199a-5p (0.975) and miR-23a-3p (0.9708). Relation between these markers, BMI and serum transaminases was also analyzed - its results are presented below in Table 13.

Table 13. Relation of miRNA molecules and obesity/NAFLD indicators in study 4.

\begin{tabular}{cccc}
\hline Molecule & Parameter & $\mathrm{r}$-value & $P$-value \\
\hline miR-223-3p & BMI & 0.39 & 0.04 \\
\hline miR-21-5p & BMI & 0.40 & 0.03 \\
\hline miR-29a-3p & BMI & 0.61 & 0.0006 \\
\hline miR-150-5p & BMI & 0.53 & 0.003 \\
\hline miR-103a-5p & BMI & 0.44 & 0.02 \\
\hline miR-34a-5p & AST & 0.45 & 0.047 \\
\hline miR-122-5p & AST & 0.50 & 0.02 \\
\hline miR-122-5p & ALT & 0.60 & 0.006 \\
\hline miR-192-5p & ALT & 0.59 & 0.006
\end{tabular}

Abbreviations: BMI, body mass index; ALT - alanin acylotransferase; AST, aspartate acylotransferase

In the cohort of this study the greatest fold change between NAFLD and healthy children occurred with miR-199a-5p (17.18), followed by third highest value of AUC parameter, although there was no significant relation between this marker and BMI, ALT and AST parameters. But bearing in mind its role in preadipocyte proliferation and differentiation, insulin signaling and correlation with state of fibrosis in human liver, miR-199a-5p still poses as a strong candidate for potential NAFLD development marker.

In contrast miR-122 scored the highest AUC and second highest fold-change (12.48) between the groups and was also positively related with both AST $(r=0.50)$ and ALT $(r=0.60)$. Previous studies in adults established its protective role in non-alcoholic steatohepatitis (NASH) [24], as well as in T2DM [25] and MODY3 [26].

Limitation of this study is the lack of comparative analysis between the NAFLD obese children and otherwise healthy obese children, as the control group consists of non-obese subjects (mean BMI: $20.11 \pm 2.5$ ). Although previously mentioned findings might be connected directly to NAFLD, the influence of obesity itself on the results cannot be ruled out.

MiR-122 was also solely investigated in study 5. in comparison to serum markers of NAFLD AST, ALT and CK18. In population of two pre-pubertal cohorts, German and Italian, both miRNA and serum markers had the similar potential of differencing NAFLD patients from healthy ones, as seen in Table 14. 
Table 14. Discriminating potential of investigated markers in two cohorts in study 5.

\begin{tabular}{cccc}
\hline COHORT $\backslash A U C$ & miR-122 & CK18 & ALT \\
\hline GC & 0.77 & 0.78 & 0.89 \\
\hline IC & 0.54 & 0.54 & 0.70 \\
\hline
\end{tabular}

Abbreviations: ALT, alanin aminotransferase; AUC, area under receiver-operator curve; CK18, cytokeratin 18; GC, German cohort; IC, Italian cohort; miR, miRNA

In both groups miR-122 matched the quality of CK18, but scored lower when compared to ALT. MiR-122 was also found to be positively correlating with BMI, AST, ALT and CK18, thus suggesting its grading possibility of NAFLD (see Table 15.). Levels of miR-122 were significantly different between patients with varied grades of NAFLD in GC $(P<0.05)$, although no such significance was found in IC.

Table 15. Correlation parameters between miRNA-122 and serum markers in study 5.

\begin{tabular}{ccccc}
\hline \multirow{2}{*}{ Marker\Group } & \multicolumn{2}{c}{ GC } & \multicolumn{2}{c}{ IC } \\
\cline { 2 - 5 } & r & $P$-value & r & $P$-value \\
\hline CK18 $(\mathrm{U} / \mathrm{l})$ & 0.40 & $0.0006^{*}$ & 0.37 & $0.0131^{*}$ \\
\hline BMI $\left(\mathrm{kg} / \mathrm{m}^{2}\right)$ & 0.25 & $0.0362^{*}$ & 0.19 & $0.0181^{*}$ \\
\hline AST $(\mathrm{U} / \mathrm{l})$ & 0.46 & $<0.0001^{*}$ & 0.36 & $0.0138^{*}$ \\
\hline ALT $(\mathrm{U} / \mathrm{l})$ & 0.45 & $<0.0001^{*}$ & 0.69 & $<0.0001^{*}$ \\
\hline GGT $(\mathrm{U} / \mathrm{l})$ & 0.31 & $0.0088^{*}$ & 0.23 & 0.1442
\end{tabular}

Abbreviations: ALT, alanin aminotransferase; AST, aspartate aminotransferase; BMI, body mass index; CK18, cytokeratin 18; GC, German cohort; GGT, glutamat-pyruvat-transaminase; IC, Italian cohort

Obtaining data from two different centers bears a risk of influencing results by differences in methodology, used tools and kits, which is a limitation of this study.

Further validation of these examinations is needed to approve these markers in clinical use, which in paediatric population would be desirable for measurement of liver steatosis and fibrosis, due to its non-invasive character, as opposed to liver biopsy [3].

\subsection{Type 2 diabetes mellitus}

Obesity stimulates increase of insulin resistance, leading to fully-developed non-insulin dependent diabetes mellitus [27]. It does so by chronic low-grade inflammation of adipose tissue, thus the anti-inflammatory treatment is able to slow its progress [28]. Genetic background of this pathological process is not yet clear, and examining this field might enable prevention of development of T2DM in obese children.

In order to establish a profile of miRNAs involved in development of this disease, two comparative analysis of miRNA expression were performed in study 6. - one between obese and lean children and second between T2DM patients and NGT adults. After serum miRNA sequencing, followed by qRT-PCR validation, expression levels of 8 miRNAs proved to be significantly different in obese children, as seen in Table 16. Relation between these 8 molecules, BMI and abdominal fat mass index (FMI) was established (Table 17). Interestingly, the highest Pearson's $r$ values were linked with miRNAs, which also presented with highest increase between groups - miR-486, miR-146b and miR-15b. 
Table 16. MiRNA levels difference between obese and lean children in study 6 .

\begin{tabular}{ccccc}
\hline Molecule & Control & Obesity & $\begin{array}{c}\text { Fold change } \\
\left(\log _{2} \text { Obesity/Control }\right)\end{array}$ & $P$ - value \\
\hline miR-222-3p & 8.28 & 18.40 & 1.15 & $<0.01$ \\
\hline miR-486-5p & 276930.75 & 643667.88 & 1.21 & $<0.01$ \\
\hline miR-146b-5p & 3.10 & 11.93 & 1.94 & $<0.01$ \\
\hline miR-146a-5p & 120.98 & 243.71 & 1.01 & $<0.01$ \\
\hline miR-20a-5p & 0.01 & 7.99 & 9.64 & $<0.05$ \\
\hline miR-15b-5p & 0.01 & 4.44 & 8.79 & $<0.01$ \\
\hline miR-26b-5p & 0.52 & 5.58 & 3.43 & $<0.01$ \\
\hline miR-197-3p & 7.35 & 2.79 & -1.41 & $<0.01$ \\
\hline
\end{tabular}

Abbreviations: miR, miRNA

Table 17. Relation between miRNAs and BMI and FMI with respective $\mathrm{r}$ and P values in study 6 .

\begin{tabular}{|c|c|c|c|c|c|c|c|c|c|}
\hline Molec & cule & $\begin{array}{c}\text { miR-222- } \\
3 p\end{array}$ & $\begin{array}{l}\text { miR-486- } \\
5 p\end{array}$ & $\begin{array}{l}\text { miR-146b- } \\
5 p\end{array}$ & $\begin{array}{c}\text { miR-15b- } \\
5 p\end{array}$ & $\begin{array}{l}\text { miR-146a- } \\
5 p\end{array}$ & $\begin{array}{l}\text { miR-20a- } \\
5 p\end{array}$ & $\begin{array}{c}\text { miR-26b- } \\
5 p\end{array}$ & $\begin{array}{c}\text { miR-197- } \\
3 p\end{array}$ \\
\hline \multirow{2}{*}{ BMI } & $\mathrm{r}$ & 0.347 & 0.575 & 0.455 & 0.697 & 0.379 & 0.323 & 0.416 & 0.383 \\
\hline & $\mathrm{P}$ & $<0.01$ & $<0.01$ & $<0.01$ & $<0.01$ & $<0.01$ & $<0.01$ & $<0.01$ & $<0.01$ \\
\hline \multirow{2}{*}{ FMI } & $\mathrm{r}$ & 0.351 & 0.542 & 0.410 & 0.494 & 0.301 & 0.375 & 0.315 & 0.234 \\
\hline & $\mathrm{P}$ & $<0.01$ & $<0.01$ & $<0.01$ & $<0.01$ & $<0.01$ & $<0.01$ & $<0.01$ & $<0.01$ \\
\hline
\end{tabular}

Abbreviations: BMI, body mass index; FMI, fat mass index; miR, miRNA;

In T2DM/NEF groups miRNA analysis, the same 3 miRNAs which were most increased in obese children turned out to be also the most overexpressed in T2DM patients, when compared to NEF ones $(\mathrm{P}<0.01)$. They were also positively related to FPG values (miR-486: $r=0.923$; miR-146b: $r=$ 0.882; miR-15b: $r=0.969$ ). ROCs and AUC parameters were prepared for each miRNA, as well as for their combination (AUC scores presented in Table 18. below).

Table 18. AUC scores of miRNA and miRNA combinations in study 6.

\begin{tabular}{ccccccc}
\hline Subject & miR-486-5p & miR-146a-5p & miR-15b-5p & $\begin{array}{c}\text { miR-486-5p/ } \\
\text { miR-146a-5p }\end{array}$ & $\begin{array}{c}\text { miR-486-5p/ } \\
\text { miR-15b-5p }\end{array}$ & $\begin{array}{c}\text { miR-146a-5p/ } \\
\text { miR-15b-5p }\end{array}$ \\
\hline AUC & 0.923 & 0.882 & 0.969 & 0.928 & 0.980 & 0.971 \\
\hline
\end{tabular}

Abbreviations: AUC, area under receiver-operator curve; miR, miRNA

Obese and diabetic model mice showed overexpression of these miRNAs in relation to development of diabetes and obesity. They were also found in heart, liver, spleen, pancreas, kidney, white fat, lung, and skeletal muscles of adult C57BL mice. MiR-486-5p added to preadipocyte culture increased their proliferation, while miR-146a-5p decreased this process and miR-15b had no significant effect. In pancreatic beta-cell dysfunction assay insulin synthesis and secretion were impaired in groups affected with miR-146a-5p and miR-15b-5p. In turn overexpression of miRNA486-5p resulted in improved glucose uptake in skeletal muscles. This study presented a panel of three miRNA markers, which together might create a promising way of grading risk of T2DM development in obese children, although these results require further validation.

Study 7. continued the research on these three miRNA molecules. After isolation from plasma of subjects, the miRNAs were then processed with RT-qPCR. The 2- ${ }^{\Delta \Delta C T}$ method was applied in order to calculate the differences of expression levels of miRNA molecules. The levels of betatrophin were 
measured using ELISA. The results of correlation parameters calculated for these potential markers and parameters useful in diagnosis of diabetes mellitus are presented below in Table 19.

Table 19. Analysis of correlations between studied miRNA molecules, betatrophin and parameters useful in diagnosis of diabetes mellitus in study 7.

\begin{tabular}{|c|c|c|c|c|c|c|c|}
\hline Group & Molecule & $\begin{array}{l}\text { Statistical } \\
\text { parameter }\end{array}$ & $\begin{array}{c}\text { BMI } \\
\text { percentile }\end{array}$ & $\begin{array}{l}\text { Glucose } \\
\text { (mg/dL) }\end{array}$ & $\begin{array}{c}\mathrm{HbA1c} \\
(\%)\end{array}$ & $\begin{array}{l}\text { Insulin } \\
(\mu \mathrm{g} / \mathrm{mL})\end{array}$ & $\begin{array}{c}\text { C- } \\
\text { Peptide } \\
(\mathrm{ng} / \mathrm{mL})\end{array}$ \\
\hline \multirow{8}{*}{ NOC } & \multirow{2}{*}{ miR-486R } & $\mathrm{r}$ & 0.282 & 0.323 & 0.271 & -0.293 & -0.176 \\
\hline & & $\mathrm{p}$ & 0.048 & 0.022 & 0.057 & 0.039 & 0.223 \\
\hline & \multirow{2}{*}{ miR-146bR } & $\mathrm{r}$ & -0.056 & 0.049 & -0.171 & -0.135 & -0.156 \\
\hline & & $\mathrm{p}$ & 0.701 & 0.736 & 0.235 & 0.351 & 0.279 \\
\hline & \multirow{2}{*}{ miR-15bR } & $\mathrm{r}$ & 0.254 & 0.130 & 0.377 & -0.450 & -0.235 \\
\hline & & $\mathrm{p}$ & 0.075 & 0.368 & 0.007 & 0.001 & 0.100 \\
\hline & \multirow{2}{*}{$\begin{array}{l}\text { Betatrophin } \\
(\mathrm{ng} / \mathrm{mL})\end{array}$} & $\mathrm{r}$ & 0.335 & 0.339 & 0.316 & 0.064 & 0.053 \\
\hline & & $\mathrm{p}$ & 0.017 & 0.016 & 0.049 & 0.661 & 0.713 \\
\hline \multirow{8}{*}{ OB } & \multirow{2}{*}{ miR-486R } & $\mathrm{r}$ & 0.335 & 0.691 & 0.785 & -0.554 & -0.424 \\
\hline & & $\mathrm{p}$ & 0.049 & 0.000 & 0.000 & 0.001 & 0.011 \\
\hline & \multirow{2}{*}{ miR-146bR } & $\mathrm{r}$ & 0.673 & 0.397 & 0.493 & -0.314 & -0.332 \\
\hline & & $\mathrm{p}$ & 0.000 & 0.018 & 0.003 & 0.046 & 0.041 \\
\hline & \multirow{2}{*}{ miR-15bR } & $\mathrm{r}$ & 0.454 & 0.483 & 0.551 & -0.359 & -0.344 \\
\hline & & $\mathrm{p}$ & 0.018 & 0.003 & 0.001 & 0.034 & 0.043 \\
\hline & \multirow{2}{*}{$\begin{array}{l}\text { Betatrophin } \\
\text { (ng/mL) }\end{array}$} & $\mathrm{r}$ & 0.376 & 0.392 & 0.363 & -0.237 & -0.124 \\
\hline & & $\mathrm{p}$ & 0.026 & 0.020 & 0.041 & 0.171 & 0.579 \\
\hline \multirow{8}{*}{$\mathrm{t} 2 \mathrm{DM}$} & \multirow{2}{*}{ miR-486R } & $\mathrm{r}$ & 0.446 & 0.564 & 0.561 & -0.371 & -0.765 \\
\hline & & $\mathrm{p}$ & 0.007 & 0.000 & 0.000 & 0.021 & 0.000 \\
\hline & \multirow{2}{*}{ miR-146bR } & $\mathrm{r}$ & 0.588 & 0.495 & 0.395 & -0.427 & -0.502 \\
\hline & & $\mathrm{p}$ & 0.000 & 0.003 & 0.019 & 0.012 & 0.002 \\
\hline & \multirow{2}{*}{$\mathrm{miR}-15 \mathrm{bR}$} & $\mathrm{r}$ & 0.388 & 0.824 & 0.669 & -0.583 & -0.355 \\
\hline & & $\mathrm{p}$ & 0.021 & 0.000 & 0.000 & 0.000 & 0.036 \\
\hline & \multirow{2}{*}{$\begin{array}{l}\text { Betatrophin } \\
(\mathrm{ng} / \mathrm{mL})\end{array}$} & $\mathrm{r}$ & 0.461 & 0.601 & 0.428 & -0.410 & -0.425 \\
\hline & & $\mathrm{p}$ & 0.005 & 0.000 & 0.032 & 0.013 & 0.011 \\
\hline
\end{tabular}

Abbreviations: BMI, body mass index; miR, miRNA; NOC, non-obese children; OB, obese children; t2DM, diabetic children 
Levels of miRNA molecules and betatrophin were positively correlated with BMI percentile, fasting glucose level and $\mathrm{HbA} 1 \mathrm{c} \%$, and negatively correlated with insulin and c-peptide levels in most of the groups. Even though these results seemed promising, studied miRNA molecules scored lower in terms of differentiating potential between non-diabetic and diabetic children, represented with AUC score (as shown in Table 20). It stands in opposition to the results of study 6., where these molecules scored significantly higher, although it is worth mentioning, that the population of the 2018 study was significantly higher. Also, the cumulative effect of molecules in differentiating was not established, contrary to the aforementioned study.

Table 20. AUC score of studied miRNA molecules in study 7.

\begin{tabular}{cccc}
\hline Molecule & miR-486 & miR-146b & miR-15b \\
\hline AUC & 0.61 & 0.54 & 0.62 \\
\hline
\end{tabular}

\subsection{Metabolic Syndrome}

Statistical analysis of correlation between miRNA molecules and parameters of obesity and MetS in study 8. identified 5 upregulated and 5 downregulated molecules, of which all were positively linked with the concentrations of adipokines. The upregulated molecules showed positive correlation with BMI, diabetic and lipid profile parameters, while downregulated ones correlated negatively with them. The exact correlation measures of miRNAs and other parameters are showed below in Table 21. and Table 22. As the MetS is the early state leading to severe changes and comorbidities in organism, adequate early detection of its development through studied molecules could enable prevention of health worsening at its very beginning.

Table 21. Correlation of miRNA molecules and adipokines in study 8

\begin{tabular}{ccccccc}
\hline \multirow{2}{*}{ miRNA } & \multicolumn{2}{c}{ Leptin } & \multicolumn{2}{c}{ Adiponectin } & \multicolumn{2}{c}{ L/A ratio } \\
\cline { 2 - 7 } & $\mathrm{R}$ & $\mathrm{p}$ & $\mathrm{R}$ & $\mathrm{p}$ & $\mathrm{R}$ & $\mathrm{p}$ \\
\hline miR-142 & 0.35 & 0.001 & 0.32 & 0.001 & 0.64 & 0.002 \\
\hline miR-140-5p & 0.25 & 0.003 & 0.44 & 0.004 & 0.51 & 0.005 \\
\hline miR-222 & 0.21 & 0.01 & 0.43 & 0.01 & 0.28 & 0.02 \\
\hline miR-143 & 0.51 & 0.001 & 0.58 & 0.001 & 0.48 & 0.001 \\
\hline miR-130 & 0.39 & 0.002 & 0.37 & 0.001 & 0.35 & 0.004 \\
\hline miR-532-5p & 0.41 & 0.002 & 0.45 & 0.001 & 0.49 & 0.001 \\
\hline miR-423-5p & 0.31 & 0.01 & 0.37 & 0.003 & 0.46 & 0.001 \\
\hline miR-520c-3p & 0.53 & 0.002 & 0.59 & 0.002 & 0.62 & 0.002 \\
\hline miR-146a & 0.21 & 0.001 & 0.26 & 0.001 & 0.29 & 0.001 \\
\hline miR-15a & 0.48 & 0.004 & 0.56 & 0.002 & 0.51 & 0.001 \\
\hline
\end{tabular}

Abbreviations: miR, miRNA 
Table 22. Correlation of miRNA molecules and MetS parameters in study 8.

\begin{tabular}{cccccccccccccc}
\hline \multirow{2}{*}{ miRNA } & \multicolumn{2}{c}{ BMI } & \multicolumn{2}{c}{ FBG } & \multicolumn{2}{c}{ Insulin } & \multicolumn{2}{c}{ HOMA-IR } & \multicolumn{2}{c}{ C-peptide } & \multicolumn{2}{c}{ LDL-C } \\
\cline { 2 - 13 } & $\mathrm{R}$ & $\mathrm{p}$ & $\mathrm{R}$ & $\mathrm{p}$ & $\mathrm{R}$ & $\mathrm{p}$ & $\mathrm{R}$ & $\mathrm{p}$ & $\mathrm{R}$ & $\mathrm{p}$ & $\mathrm{R}$ & $\mathrm{p}$ \\
\hline miR-142 & 0.54 & 0.0001 & 0.29 & 0.0001 & 0.22 & 0.0001 & 0.32 & 0.0001 & 0.28 & 0.001 & 0.32 & 0.0001 \\
\hline miR-140-5p & 0.42 & 0.0001 & 0.34 & 0.0001 & 0.27 & 0.0001 & 0.34 & 0.0001 & 0.38 & 0.001 & 0.35 & 0.0001 \\
\hline miR-222 & 0.43 & 0.0001 & 0.18 & 0.0001 & 0.11 & 0.0001 & 0.13 & 0.0001 & 0.41 & 0.001 & 0.36 & 0.001 \\
\hline miR-143 & 0.38 & 0.0001 & 0.21 & 0.0001 & 0.28 & 0.0001 & 0.33 & 0.0001 & 0.25 & 0.001 & 0.37 & 0.001 \\
\hline miR-130 & 0.31 & 0.0001 & 0.26 & 0.0001 & 0.23 & 0.0001 & 0.35 & 0.0001 & 0.52 & 0.001 & 0.29 & 0.0001 \\
\hline miR-532-5p & -0.48 & 0.0001 & -0.14 & 0.001 & -0.35 & 0.001 & -0.25 & 0.0001 & -0.18 & 0.001 & 0.21 & 0.001 \\
\hline miR-423-5p & -0.65 & 0.0001 & -0.29 & 0.001 & -0.37 & 0.001 & -0.31 & 0.0001 & -0.31 & 0.001 & 0.23 & 0.001 \\
\hline miR-520c-3p & -0.38 & 0.0001 & -0.32 & 0.001 & -0.41 & 0.001 & -0.35 & 0.0001 & -0.37 & 0.001 & 0.22 & 0.001 \\
\hline miR-146a & -0.46 & 0.0001 & -0.38 & 0.001 & -0.48 & 0.001 & -0.43 & 0.0001 & -0.46 & 0.001 & 0.216 & 0.001 \\
\hline miR-15a & -0.41 & 0.0001 & -0.28 & 0.001 & -0.56 & 0.001 & -0.46 & 0.0001 & -0.29 & 0.001 & 0.193 & 0.001
\end{tabular}

Abbreviations: BMI, body mass index; FBG, fasting blood glucose; HOMA-IR, homeostatic model assessment of insulin resistance; miR, miRNA; LDL-C, low-density lipoprotein cholesterol

\subsection{Atherosclerosis}

Cholesterol efflux is a mechanism of cholesterol transfer from macrophages to HDL, which has inhibiting role in creation of foam cells and thus preventing development of atherosclerotic plaques. ATP-binding cassette transporters A1/G1 (ABCA1/ABCG1) are involved in this process [29].

Study 7. identified 6 miRNAs significantly $(P<0.05)$ correlated with cholesterol efflux capacity, of which 2 positively (miR-3129-5p; miR-20b) and 4 negatively (miR-9-5p; miR-320d; miR-301a-5p; miR-155-5p). They are presented below in Table 23. with respective $\beta$ and $r$ values.

Table 23. Correlation of miRNAs and cholesterol efflux with values of linear regression $\mathrm{r}$ and $\beta$ in study 9.

Subject miR-3129-5p miR-20b miR-9-5p miR-320d miR-301a-5p miR-155-5p

\begin{tabular}{ccccccc}
\hline $\mathrm{r}$ & 0.72 & 0.21 & -0.16 & 0.37 & 0.10 & 0.20 \\
\hline$\beta$ & 0.695 & 0.430 & 0.15 & -0.19 & 0.068 & 0.004 \\
\hline
\end{tabular}

Abbreviations: miR, miRNA

Interestingly, each of these molecules targets ABCA1 genes expression. Comparison of cholesterol efflux linked genes expression in model macrophages affected by VAT-derived EVs showed no differences between EVs of obese and lean subjects, although treatment with EVs itself caused differences in expression between experiment and control groups, as well as among the experiment groups treated with different EV concentration $(3 \mu \mathrm{g} / \mathrm{mL}$ and $1 \mu \mathrm{g} / \mathrm{mL})$.

Although the study identified a panel of miRNAs of significant level of variety among high and low cholesterol efflux capacity subjects, results of this study lack the correlation to BMI and obesity in subjects to be treated as relevant for prediction of atherosclerosis development risk in obese children.

\section{Summary}

Review of literature provided us with a good insight into the possibilities of applying miRNA molecules in diagnosis and treatment. 
- Although reviewed studies did not present any relevant miRNA molecule markers for diagnosing ED, miR-630 was shown to influence the condition of endothelium, therefore posing as a strong candidate for future therapeutic strategy for ED

- Two miRNA molecules: miR-199a-5p and miR-122, presented a good potential in diagnosis of NAFLD and grading its development, however further evaluations are recommended

- Studies concerning type 2 diabetes mellitus suggested miR-486, miR-146b and miR-15b as markers of disease progression, although the efficacy of these molecules differed between the studies (AUC: $0.88-0.98$ in study 6 . vs $0.54-0.62$ in study 7.)

- MiRNA molecules examined in study 8. showed significant correlation with parameters of metabolic syndrome (BMI, diabetic and lipid profile parameters), which might be used for early detection and planning adequate prevention of this disease

- Research on link between miRNA molecules and atherosclerosis development returned no satisfying results

Results of studies mentioned above convince that miRNA might play an important role in controlling and stopping the progression of obesity comorbidities in paediatric population, especially ED, NAFLD, T2DM.

Funding: This research received no external funding.

Conflicts of Interest: The authors declare no conflict of interest.

\section{References}

1. Garrido-Miguel, M.; Oliveira, A. Prevalence of Overweight and Obesity among European Preschool Children: A Systematic Review and Meta-Regression by Food Group Consumption. Nutrients 2019, 11(7), 1698.

2. Umer, A.; Kelley, G.A. Childhood obesity and adult cardiovascular disease risk factors: a systematic review with meta-analysis. BMC Public Health 2017, 17, 683.

3. Jain, A. Pediatric Fatty Liver Disease. Mo Med 2019, 116(2), 123-128.

4. Gray, L.J;; Brady, E.M. Evaluation and refinement of the PRESTARt tool for identifying 12-14 year olds at high lifetime risk of developing type 2 diabetes compared to a clinicians assessment of risk: a crosssectional study. BMC Endocr Disord 2019, 19, 79.

5. Freye, S. S.; Fernandez-Mendoza, J. Childhood obesity, weight loss and developmental trajectories predict the persistence and remission of childhood sleep-disordered breathing. Pediatr Obes 2019, 14(1), 10.1111/ijpo.12461.

6. Pordzik, J.; Jakubik D. Significance of circulating microRNAs in diabetes mellitus type 2 and platelet reactivity: bioinformatic analysis and review. Cardiovasc Diabetol 2019, 18, 113.

7. Syeda, Z.A.; Saratu' Langden, S.S. Regulatory Mechanism of MicroRNA Expression in Cancer. Int. J. Mol. Sci 2020, 21(5), 1723.

8. Liang, Ch-Y.; Li Z-Y. Downregulation of hsa-microRNA-204-5p and identification of its potential regulatory network in non-small cell lung cancer: RT-qPCR, bioinformatic- and meta-analyses. Respir Res 2020, 21, 60 .

9. Ouyang, S.; Tang, R. Characterization and predicted role of microRNA expression profiles associated with early childhood obesity. Mol Med Rep 2017, 16(4), 3799-3806.

10. Shi, Ch.; Zhang, M. miR-148a is Associated with Obesity and Modulates Adipocyte Differentiation of Mesenchymal Stem Cells through Wnt Signaling. Sci Rep 2015, 5, 9930.

11. Donghui, T.; Shuang, B. Improvement of microvascular endothelial dysfunction induced by exercise and diet is associated with microRNA-126 in obese adolescents. Microvascular Research 2019, 123, 8691.

12. Khalyfa, A.; Kheirandish-Gozal, L. Circulating microRNAs as Potential Biomarkers of Endothelial Dysfunction in Obese Children. Chest 2016, 149(3), 786-800.

13. Khalyfa, A.; Kheirandish-Gozal, L. Circulating Plasma Extracellular Microvesicle MicroRNA Cargo and Endothelial Dysfunction in Children with Obstructive Sleep Apnea. AmJ Respir Crit Care Med 2016, 194(9), 1116-1126. 
14. Thompson, M.D.; Cismowski, M.J. Elevation of circulating microRNA levels in obese children compared to healthy controls. Clinical Obesity 2017, 7(4), 216-221.

15. Brandt, S.; Roos, J. Circulating levels of miR-122 and nonalcoholic fatty liver disease in pre-pubertal obese children. Pediatric Obesity 2018, 13(3), 175-182.

16. Cui, X.; You, L. Change in circulating microRNA profile of obese children indicates future risk of adult diabetes. Metabolism 2018, 78, 95-105.

17. Mohany, K.; Al Rugaie, O. Association between circulating microRNAs 486, 146b and 15b and serum betatrophin levels in obese; type 2 diabetic and non-diabetic children. BMC Endocr Disord 2020, 20, 145

18. Al-Rawaf, H.A. Circulating microRNAs and adipokines as markers of metabolic syndrome in adolescents with obesity. Clinical Nutrition 2019, 38(5), 2231-2238

19. Barberio, M.D.; Kasselman, L.J. Cholesterol efflux alterations in adolescent obesity: role of adiposederived extracellular vesical microRNAs. J Transl Med 2019, 17, 232.

20. Rochlani, Y.; Pothineni, N.V. Metabolic syndrome: pathophysiology, management, and modulation by natural compounds. Ther Adv Cardiovasc Dis 2017, 11(8), 215-225

21. Mueller, U.M.; Walther, C. Endothelial Function in Children and Adolescents Is Mainly Influenced by Age, Sex and Physical Activity - An Analysis of Reactive Hyperemic Peripheral Artery Tonometry. Circulation Journal 2017, 81(5), 717-725.

22. Hussain, A.; Gul, M.A. Validation of Novel Fibrosis Index (NFI) for assessment of liver fibrosis: comparison with transient elastography (FibroScan). BMJ Open Gastroenterol 2019, 6(1), e000316.

23. Newsome, P.N.; Sasso, M. FibroScan-AST (FAST) score for the non-invasive identification of patients with non-alcoholic steatohepatitis with significant activity and fibrosis: a prospective derivation and global validation study. Lancet Gastroenterol Hepatol 2020, 5(4), 362-373.

24. Jin, X.; Gao, J. Antagonizing circRNA_002581-miR-122-CPEB1 axis alleviates NASH through restoring PTEN-AMPK-mTOR pathway regulated autophagy. Cell Death Dis 2020, 11(2), 123.

25. Huang, X.; Gong, S. Lower Circulating miR-122 Level in Patients with HNF1A Variant-Induced Diabetes Compared with Type 2 Diabetes. J Diabetes Res 2018, 2018, 7842064.

26. Hu, M.; Huang, X. Loss of HNF1 $\alpha$ Function Contributes to Hepatocyte Proliferation and Abnormal Cholesterol Metabolism via Downregulating miR-122: A Novel Mechanism of MODY3. Diabetes Metab Syndr Obes 2020, 13, 627-639.

27. Smith, G.I.; Polidori, D.C. Influence of adiposity, insulin resistance and intrahepatic triglyceride content on insulin kinetics. J Clin Invest 2020.

28. Lee, J.M.; Choi, S.S. Broussonetia papyrifera Root Bark Extract Exhibits Anti-inflammatory Effects on Adipose Tissue and Improves Insulin Sensitivity Potentially Via AMPK Activation. Nutriens 2020, 12(3), 773.

29. Ren, K.; Li, H. Mangiferin promotes macrophage cholesterol efflux and protects against atherosclerosis by augmenting the expression of ABCA1 and ABCG1. Aging (Albany NY) 2019, 11(23), 10992-11009. 